\title{
The swelling transition of
} lepidocrocite-type protonated layered titanates into anatase under hydrothermal treatment

\author{
Huiyu Yuan, Rogier Besselink, Zhaoliang Liao \& Johan E. ten Elshof
}

MESA+ Institute for Nanotechnology, University of Twente, P.O. Box 217, 7500 AE Enschede, the Netherlands.

The common facets of anatase crystals are the (001) and (101) planes. However, the phase transformation from lepidocrocite-type titanate into anatase by hydrothermal processing yields an anatase microstructure with high concentration of exposed (010) planes. The phase transformation of a lepidocrocite-type protonated layered titanate (HTO) into anatase was studied using XRD, TEM, FTIR, and measurement of $\mathrm{pH}$ and zeta potential. It was found that HTO is proton-deficient. The phase transformation process begins after uptake of a sufficient number of protons into the lepidocrocite-type structure. With the uptake of protons new hydroxyl groups form on the internal surfaces of the layered titanate and result in a bilayer state of HTO. The phase transformation reaction is a topotactic dehydration reaction in which anatase forms and water is expelled by syneresis.

T itanium dioxide $\left(\mathrm{TiO}_{2}\right)$ is receiving a lot of attention because of its promising photocatalytic properties that may possibly find applications in dye-sensitized solar cells, photoelectrochemical conversion cells and the photocatalytic decomposition of hazardous organic species ${ }^{1-6}$. Anatase-type $\mathrm{TiO}_{2}$ has been studied intensively for photocatalytic applications because of its high photoreactivity, especially on (010) planes ${ }^{7}$. However, anatase bulk crystals normally expose their (001) and (101) planes rather than their (010) planes ${ }^{8}$. Recently, it was found that anatase crystals prepared by hydrothermal treatment from layered lepidocrocite-type titanates $\mathrm{H}_{1.07} \mathrm{Ti}_{1.73} \mathrm{O}_{4} \cdot \mathrm{nH}_{2} \mathrm{O}$ and $\mathrm{H}_{0.68} \mathrm{Ti}_{1.83} \mathrm{O}_{4} \cdot \mathrm{nH}_{2} \mathrm{O}$, or their individual 2D titanate nanosheets, preferentially expose their $(010)$ planes at the crystal surface ${ }^{9-11}$. Anatase prepared from layered titanates and nanosheets showed high photocatalytic activity and a high adsorption capacity of the N719 dye that is used in dye-sensitized solar cells $\mathrm{s}^{9-11}$.

The formation mechanism of anatase has been considered to involve an in situ topotactic transformation reaction in the crystal bulk of the layered titanate $\mathrm{H}_{1.07} \mathrm{Ti}_{1.73} \mathrm{O}_{4} \cdot \mathrm{nH}_{2} \mathrm{O}^{12}$. It has been proposed that a distorted layered structure is formed during hydrothermal treatment, which is subsequently transformed into a distorted anatase structure, and subsequently into the normal anatase structure ${ }^{13}$. However, details of the topotactic phase transformation mechanism are lacking. Such information could help in preparing new materials by this approach. We studied the phase transformation from lepidocrocite-type titanates to anatase with $\mathrm{H}_{1.07} \mathrm{Ti}_{1.73} \mathrm{O}_{4} \cdot \mathrm{nH}_{2} \mathrm{O}$ (HTO) as model compound because of its simple structure among the topotactic reactants ${ }^{11,13,14}$. HTO can easily be obtained from $\mathrm{K}_{0.8}\left[\mathrm{Ti}_{1.73} \mathrm{Li}_{0.27} \mathrm{O}_{4}\right]$ (KLTO) by an ion exchange reaction ${ }^{15,16}$. KLTO is composed of corrugated host layers of edge-sharing $\mathrm{TiO}_{6}$ octahedra and interlayer $\mathrm{K}^{+}$ions compensating for the negative charge of the $\mathrm{TiO}_{6}$ octahedral layers, wherein $\mathrm{Li}^{+}$ions occupy $13.5 \%$ of the Ti octahedral sites in the host layers, as shown in Figure 1. Only $40 \%$ of the potassium positions shown in Figure 1 are occupied ${ }^{15}$. After protonation a monolayer of water and $\mathrm{H}_{3} \mathrm{O}^{+}$occupies the interlayer space instead of alkali ions ${ }^{15}$.

In the present paper the behavior of lepidocrocite-type protonated layered titanates derived from KLTO under hydrothermal treatment is reported. We present details of the topotactic reaction of lepidocrocite-type titanates to anatase during hydrothermal treatment. Our results show that the process first goes through a stage of protons uptake, which causes swelling of the layered material. Then, with increasing concentration of protons at a suitable temperature the topotactic phase transformation reaction occurs. It is noted that this work focuses on the phase evolution prior to and in the early stages of transformation rather than on the stage after the dehydration reaction. Details of the phase transformation after topotactic reaction can be found in the work of Wen et al. ${ }^{13}$ 

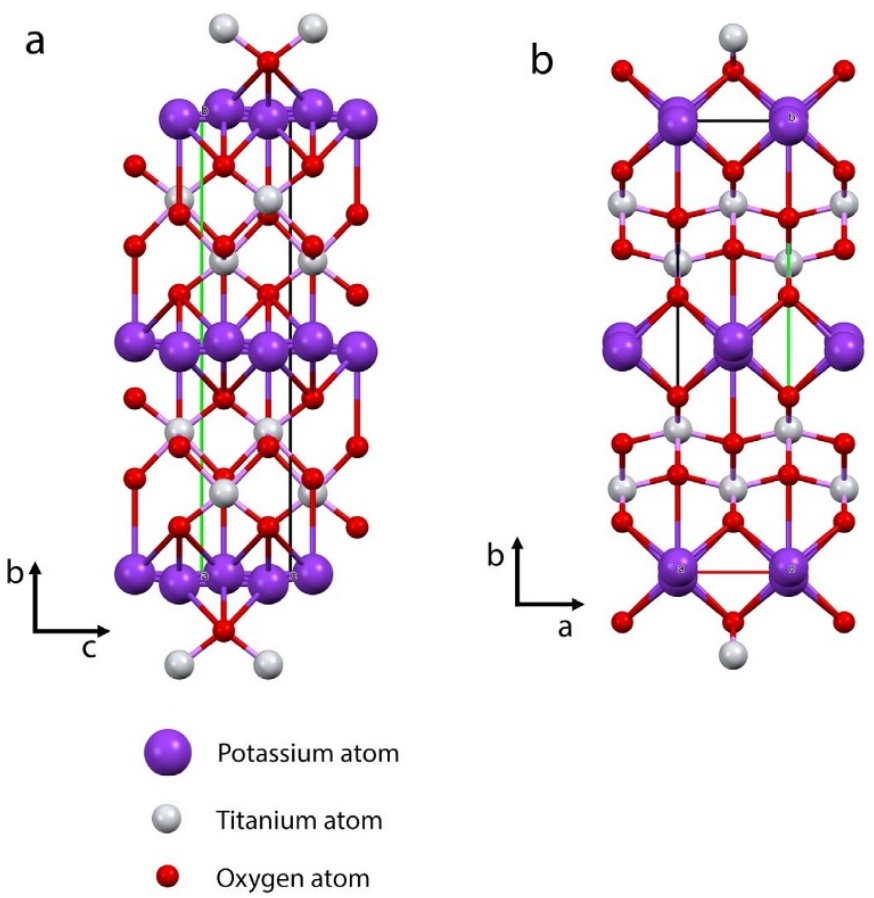

Figure 1 The crystal structure of KLTO viewed along (a) a axis and (b) c axis.

\section{Results}

The uptake of protons and swelling of the layered structure. We performed a series of experiments to investigate the influence of hydrothermal treatment temperature on HTO pre-dried at room temperature (further denoted as HTO RT) in aqueous solutions at $80-120^{\circ} \mathrm{C}$. Figure $2 \mathrm{a}$ shows the XRD pattern of HTO RT. It is consistent with a protonated titanate with one hydrous layer ${ }^{15,17}$. The peak at $2 \theta=9.59^{\circ}$ indicates that the basal spacing between the layers is $0.92 \mathrm{~nm}$. Figure $2 \mathrm{~b}$ shows that after HTO RT was hydrothermally treated at $80^{\circ} \mathrm{C}$, a small peak corresponding with a basal spacing of $1.15 \mathrm{~nm}$ was observed at $2 \theta=7.72^{\circ}$, suggesting an expansion of the interlayer distance between the titanate planes of

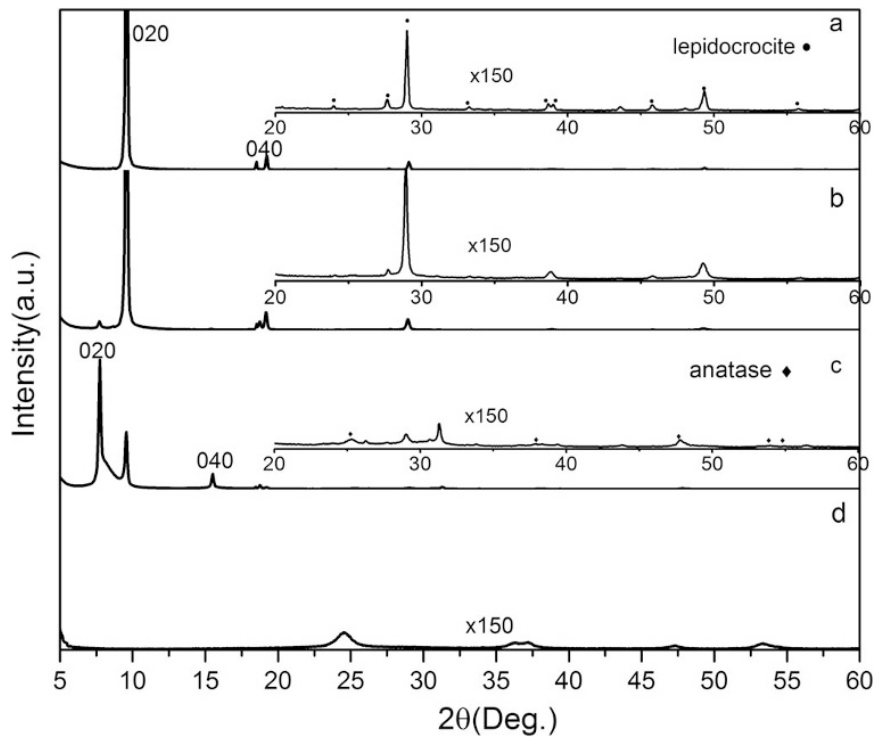

Figure $2 \mid$ X-ray diffraction patterns of HTO RT in wet state. (a) HTO RT, (b) HTO RT after hydrothermal treatment at $80^{\circ} \mathrm{C}$, (c) HTO RT after hydrothermal treatment at $120^{\circ} \mathrm{C}$, and (d) HTO RT after repetitive hydrothermal treatment at $120^{\circ} \mathrm{C}$.
HTO. The increase of $\sim 0.20 \mathrm{~nm}$ is approximately equal to the molecular size of water $(\sim 0.25 \mathrm{~nm})^{18}$. At a hydrothermal treatment temperature of $120^{\circ} \mathrm{C}$, the peak intensity increased by a factor of $\sim 16$ compared to the peak intensity of a sample prepared at $80^{\circ} \mathrm{C}$ (Figure 2c). This indicates that the swollen phase was the dominant phase at $120^{\circ} \mathrm{C}$. The shoulder between the peaks at $2 \theta=$ $7.72^{\circ}$ and $9.59^{\circ}$ implies that the new phase was derived from HTO RT. Also traces of the anatase phase can be observed in Figure 2c. Figure 2d shows the XRD pattern of HTO RT after repetitive hydrothermal treatment at $120^{\circ} \mathrm{C}$, which is discussed in more detail below.

The $\mathrm{pH}$ change after $24 \mathrm{~h}$ of hydrothermal treatment as a function of treatment temperature is shown in Figure 3. It is noted that no further $\mathrm{pH}$ changes occurred when the hydrothermal treatment process was prolonged beyond $24 \mathrm{~h}$. The data revealed an increasing $\mathrm{pH}$ with increasing hydrothermal treatment temperature, with an anomaly around $100^{\circ} \mathrm{C}$. Repeated hydrothermal experiments at $100^{\circ} \mathrm{C}$ resulted in final $\mathrm{pH}$ values of 7.2, 7.3, 7.6 and 7.7. Hence, the change of $\mathrm{pH}$ below $100^{\circ} \mathrm{C}$ was limited to around $\mathrm{pH}=8$, although the trend would predict a higher $\mathrm{pH}$. The final $\mathrm{pH}$ increased further at temperatures above $100^{\circ} \mathrm{C}$. The trend in $\mathrm{pH}$ indicates a decreasing proton concentration in the solution with increasing treatment temperature. The reduced proton concentration may have been caused by a competitive uptake of protons by the surface $\mathrm{O}^{-}$groups of the titanate planes of HTO. This agrees with the XRD data, which suggest an increased spacing between the HTO layers. This swelling process is most likely caused by the effect of the uptake of $\mathrm{H}_{3} \mathrm{O}^{+}$ions.

From lepidocrocite-type titanate to anatase. One sample was first given a single hydrothermal treatment at $120^{\circ} \mathrm{C}$ for $24 \mathrm{~h}$, after which it was titrated with $2 \mathrm{M} \mathrm{HNO}_{3}$ acid solution to adjust the $\mathrm{pH}$ of the solution to 2.8. Then a second hydrothermal treatment was applied. It was observed that no more protons were absorbed after repetitive hydrothermal treatment at $120^{\circ} \mathrm{C}$ because the $\mathrm{pH}$ remained constant. The FTIR spectrum of the supernatant after hydrothermal treatment shows that no additional products were observed in the solution besides water and nitrate ions. The XRD pattern of the final state of the powder product is presented in Figure $2 \mathrm{~d}$. The diffractogram indicates that an anatase-type $\mathrm{TiO}_{2}$ phase has formed. The broad and low intensity peaks indicate a low degree of crystallinity.

The microscopic structure of HTO-RT after repetitive hydrothermal treatment at $120^{\circ} \mathrm{C}$ was further investigated by transmission electron microscopy (TEM). A typical high resolution image of the

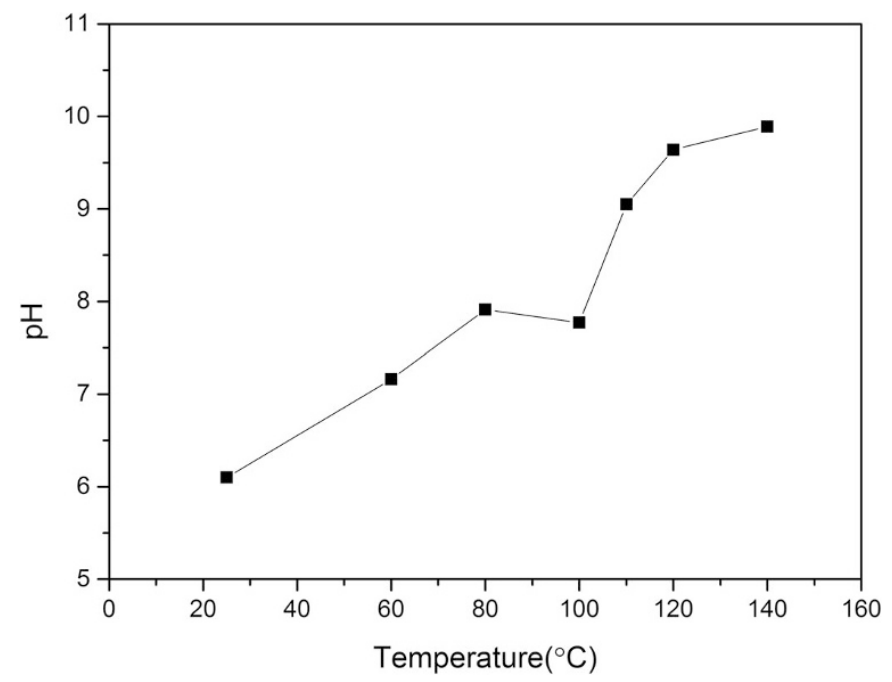

Figure 3 | pH of HTO RT solutions after 24 h hydrothermal treatment at different temperatures. 


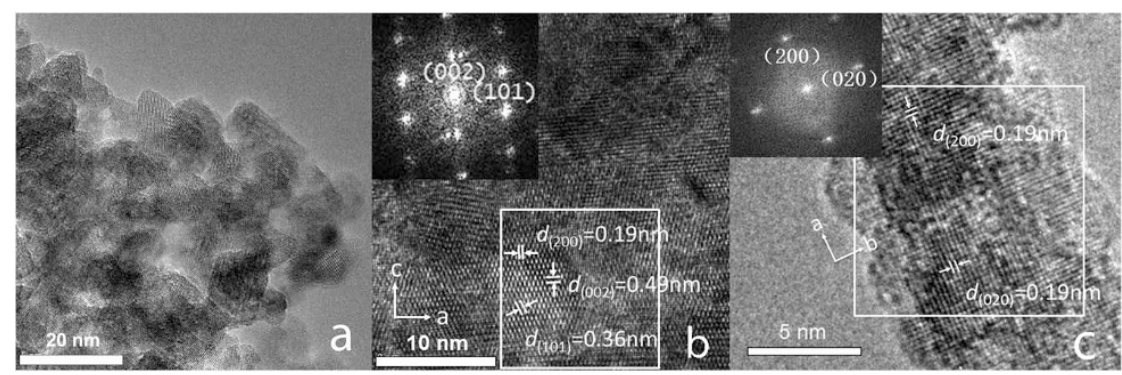

Figure $4 \mid$ (a) TEM image of anatase-type $\mathrm{TiO}_{2}$ derived from HTO RT with repetitive hydrothermal treatment at $120^{\circ} \mathrm{C}$; (b)-(c) $\mathrm{HRTEM}$ images of (010) and (001) oriented nanocrystals, respectively.

as-formed powder in Figure 4a indicates that the product was polycrystalline and the average grain size was about $10 \mathrm{~nm}$. The small grain size is in agreement with the broad peaks observed with XRD as shown in Figure 2d. The crystal structure of each grain was analyzed by performing a fast Fourier transform (FFT) on the high resolution TEM (HRTEM) image. Two kinds of crystalline planes, i.e. (010) and (001), were observed in the TEM images. Figure $4 \mathrm{~b}$ shows an example of a (010) oriented anatase nanocrystal. The plane distances were determined to be $\mathrm{d}_{(002)}=0.49 \mathrm{~nm}$ and $\mathrm{d}_{(101)}=0.36 \mathrm{~nm}$, indicating an $(010)$ oriented plane ${ }^{13}$. The FFT at the left top panel of Figure $4 \mathrm{~b}$ also revealed that the zone axis is [010] and thus the plane which is vertical to the TEM electron beam is (010). The HRTEM image of a (001) oriented nanocrystal is shown in Figure 4c. The FFT revealed a lattice structure with $\mathrm{d}_{(200)}=\mathrm{d}_{(020)}=0.19 \mathrm{~nm}$, which is the same as the bulk value. In our TEM investigation, we found that most of the external surface could be identified as (010) surface plane, and only a minor fraction of the surface was found to be (001) plane. Therefore, the nanocrystals preferentially exhibit their (010) facets.

The mechanism of phase transformation. The zeta potential of HTO RT as function of $\mathrm{pH}$ is shown in Figure 5. The zeta potential of anatase is shown for the sake of comparison. The zeta potential is related to surface charge characteristics of the external HTO surface. It can be seen that the point of zero charge (pzc) of HTO RT was 3.1. In comparison, the pzc of anatase with particle sizes of $15 \mathrm{~nm}$ (Figure 5) is approximately $6.0^{19}$. Hence, HTO is much more acidic than anatase. At $\mathrm{pH}>3$ the external surface of the HTO grains is proton-deficient. Remarkably, we observed substantial uptake of protons by HTO from solutions with a starting $\mathrm{pH}$ of 2.8 upon hydrothermal treatment, with a resulting increase in $\mathrm{pH}$ up to

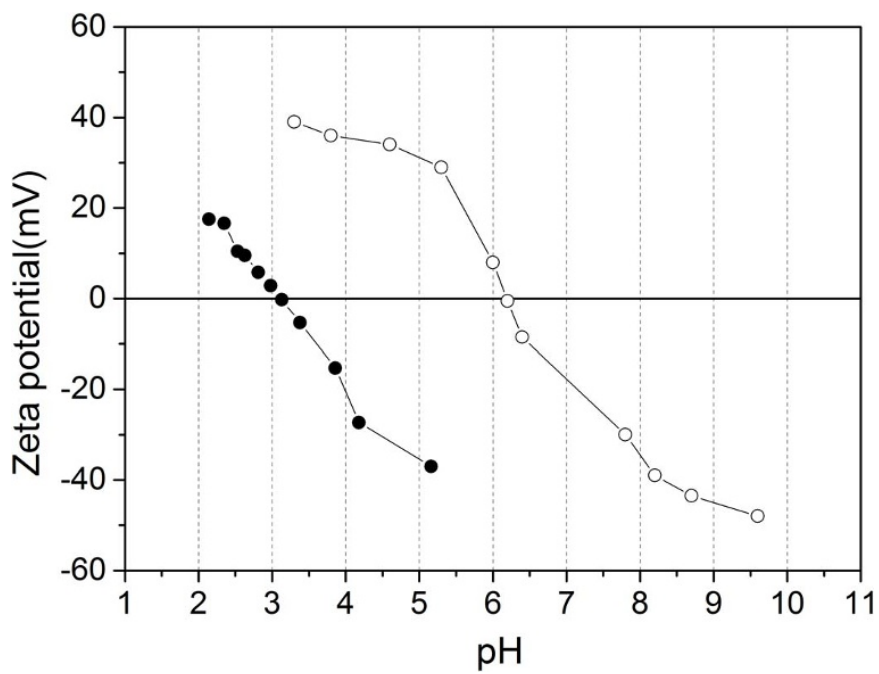

Figure 5 | Variation of zeta potential of HTO RT and anatase with $\mathrm{pH}$ : ๑, HTO RT; $\bigcirc$, anatase. Data for anatase are taken from ref. 19. values of $\sim 10$. Since the external grain surfaces of HTO are protondeficient at $\mathrm{pH}$ value of 10 , it must be the inner surface planes of HTO RT that absorb protons strongly. The proton exchange behavior of the external HTO surfaces and the internal HTO planes is therefore completely different. Casarin et al. investigated multilayer structures of protonic titanate nanosheets $\mathrm{H}_{2} \mathrm{Ti}_{3} \mathrm{O}_{7}$ with a step structure by first principles calculations ${ }^{20}$. They found that two ribbon oxygen atoms on adjacent inner surfaces of $\mathrm{H}_{2} \mathrm{~T}_{3} \mathrm{O}_{7}$, which have a similar bond configuration as the ribbon oxygen atoms in HTO, share a hydrogen atom in the form of a hydroxyl bond and a hydrogen bond. The results of our study are in agreement with their conclusions.

For the sake of comparison HTO dried at $80^{\circ} \mathrm{C}$ (further denoted as HTO HT) was also hydrothermally treated. HTO HT has a smaller interlayer spacing than HTO RT because it contains less interlayer water $^{21}$. Several reports concluded that dehydrated layered materials cannot be intercalated by chemical means because of the strong electrostatic force between the titanate layers and the proton counter ions $^{21-23}$. Figure 6 shows the corresponding XRD data. The peak of HTO RT at $2 \theta=9.59^{\circ}$ shifted to $2 \theta=12.42^{\circ}$ in HTO HT (Figure 6a), indicating that the basal spacing of $0.92 \mathrm{~nm}$ of HTO RT decreased to $0.71 \mathrm{~nm}$ upon dehydration (HTO HT). The decrease of $0.21 \mathrm{~nm}$ is close to the $\sim 0.25 \mathrm{~nm}$ thickness of a single molecular layer of water ${ }^{18}$. The XRD patterns of HTO HT after hydrothermal treatment at $80^{\circ} \mathrm{C}$ and $120^{\circ} \mathrm{C}$ are shown in Figure $6 \mathrm{~b}$ and Figure $6 \mathrm{c}$, respectively. A similar peak appeared at $2 \theta=7.72^{\circ}(\mathrm{d}=1.15 \mathrm{~nm})$ as for HTO RT after hydrothermal treatment at $80-120^{\circ} \mathrm{C}$ (Figure $2 \mathrm{~b}, \mathrm{c}$ ). The correspondence indicates that a structure with the same large plane

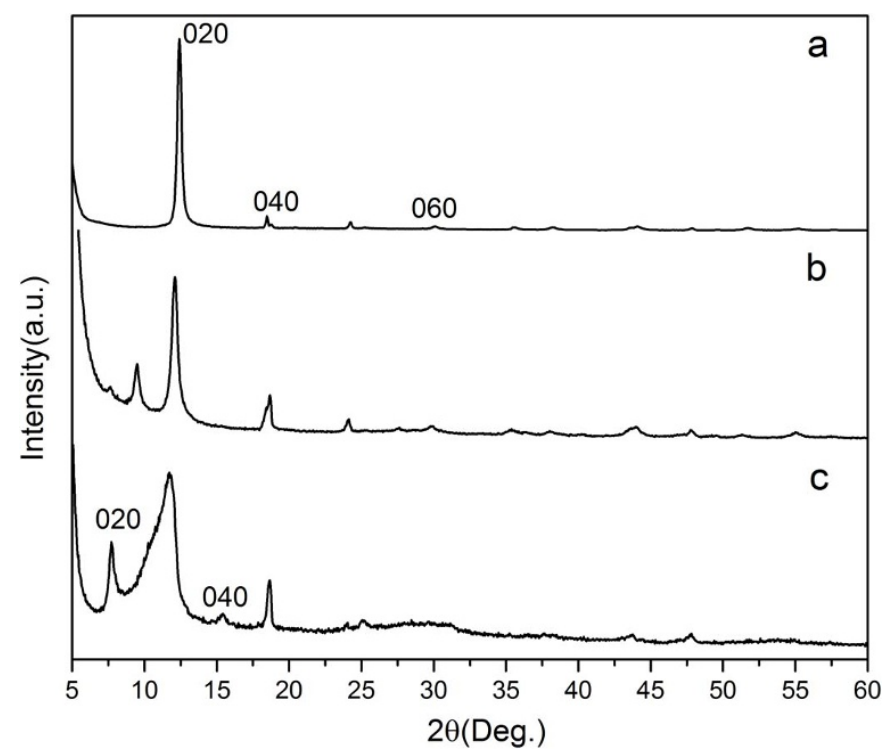

Figure $6 \mid$ X-ray diffraction patterns of HTO HT. (a) HTO HT in dry state, (b) HTO HT in wet state after hydrothermal treatment at $80^{\circ} \mathrm{C}$, and (c) at $120^{\circ} \mathrm{C}$. 
spacing formed upon hydrothermal treatment, irrespective of whether the initial sample was HTO RT or HTO HT. However, while the major part of the HTO RT material appears to transform to the state with a large lattice spacing of $1.15 \mathrm{~nm}$, only a minor part of the HTO HT material phase appears to do that. The larger part of the HTO HT material appears to remain in a swollen state of the original dry HTO HT structure with a lattice spacing of $0.71 \mathrm{~nm}$. As shown in Figure 6 , the original peak of dry HTO HT at $2 \theta=12.42^{\circ}$ shifted to slightly lower angles and broadened so that a shoulder formed at lower $2 \theta$. This is a very strong indication of swelling caused by interaction with water. Apparently, the ability of the HTO HT structure to swell is smaller than that of HTO RT. This is probably due to the presence of a barrier to swelling in the HTO HT samples due to strong electrostatic forces ${ }^{21-23}$. The initial $\mathrm{pH}$ of 8.3 of a dispersion of HTO HT in water increased to 8.8 and 9.5 after hydrothermal treatment at $80^{\circ} \mathrm{C}$ and $120^{\circ} \mathrm{C}$, respectively, which indicates that HTO HT is proton-deficient and absorbs protons during hydrothermal treatment just like HTO RT. Nevertheless, the swelling of HTO HT demonstrates that the driving force for the uptake of protons is large, which implies that the process involves a chemical reaction between host layers and protons.

Based on the discussion above, we propose that the bonding configuration changes upon hydrothermal treatment: 1) Before hydrothermal treatment of HTO RT the two oxygen atoms on an adjacent titanate sheet share one hydrogen atom, which forms a hydroxyl bond with one oxygen atom and a hydrogen bond with the other oxygen; 2) During hydrothermal treatment absorbed protons form hydroxyl groups with the hydrogen-bond oxygen atoms on the inner surfaces of titanate layers. A bilayer hydroxyl bond configuration forms when all the oxygen atoms on the inner surfaces of titanate layers are bonded to their own hydrogen atom.

To validate this hypothesis, FTIR was used to characterize the bonding configuration. Figure 7 shows the FTIR results of HTO RT before and after hydrothermal treatment at $120^{\circ} \mathrm{C}$. The FTIR spectra of anatase derived from HTO RT are also shown. The data indicate that two broad bands around 3400 and $1640 \mathrm{~cm}^{-1}$, which are assigned to stretching and bending vibrations of $\mathrm{H}_{2} \mathrm{O}$ and/or $\mathrm{H}_{3} \mathrm{O}^{+}$, respectively ${ }^{24}$, did not change intensity upon hydrothermal treatment. On the other hand, the peak at $920 \mathrm{~cm}^{-1}$ shifted to $880 \mathrm{~cm}^{-1}$ and increased significantly in intensity after hydrothermal treatment at $120^{\circ} \mathrm{C} . \mathrm{H}_{2} \mathrm{Ti}_{3} \mathrm{O}_{7}, \mathrm{H}_{2} \mathrm{Ti}_{4} \mathrm{O}_{9} \cdot 1.2 \mathrm{H}_{2} \mathrm{O}$, and $\mathrm{H}_{2} \mathrm{Ti}_{5} \mathrm{O}_{11} \cdot 3 \mathrm{H}_{2} \mathrm{O}$ with a zigzag structure have been reported to exhibit a characteristic sorption band at $950-1000 \mathrm{~cm}^{-1}$, which was attributed to the bending mode of hydroxyl groups ${ }^{15}$. Based on that interpretation, Sasaki et al. ${ }^{15,16,26}$ concluded that no hydroxyl groups are present in lepidocrocite-type protonated layered titanates since no peaks are observed in that range of $950-1000 \mathrm{~cm}^{-1}$. However, it is noteworthy that the present material has a planar rather than a zigzag structure. The basicity of the oxygen atoms on the planar structure is lower than the nonshared oxygen atoms at the stepping corner in the zigzag structure ${ }^{16}$. The reduced basicity results in a weaker $\mathrm{O}-\mathrm{H}$ bond, thus reducing the force constant of the O-H vibration. This implies that the peak that can be assigned to the hydroxyl group is present at a lower wave number than in the zigzag structures. This agrees with our observation of a peak at $880 \mathrm{~cm}^{-1}$. We recorded the FTIR spectrum of HTO-derived anatase to rule out the possibility that the peak at $880 \mathrm{~cm}^{-1}$ is associated with anatase. Hence, the peak at $920 \mathrm{~cm}^{-1}$ in Figure 7 may be assigned to hydroxyl groups. Upon hydrothermal treatment the intensity of the peak increased significantly, and the interpretation agrees well with the observed $\mathrm{pH}$ change and the XRD data. Furthermore, the peak shift from $920 \mathrm{~cm}^{-1}$ to $880 \mathrm{~cm}^{-1}$ which indicates that the bending strength of the $\mathrm{O}-\mathrm{H}$ groups weakened upon hydrothermal treatment. To our best knowledge, the stability of fully hydroxylated lepidocrocite-type titanates has not been reported till date. However, it is known that bilayer (001)-oriented anatase films can be converted through a barrierless pathway into a

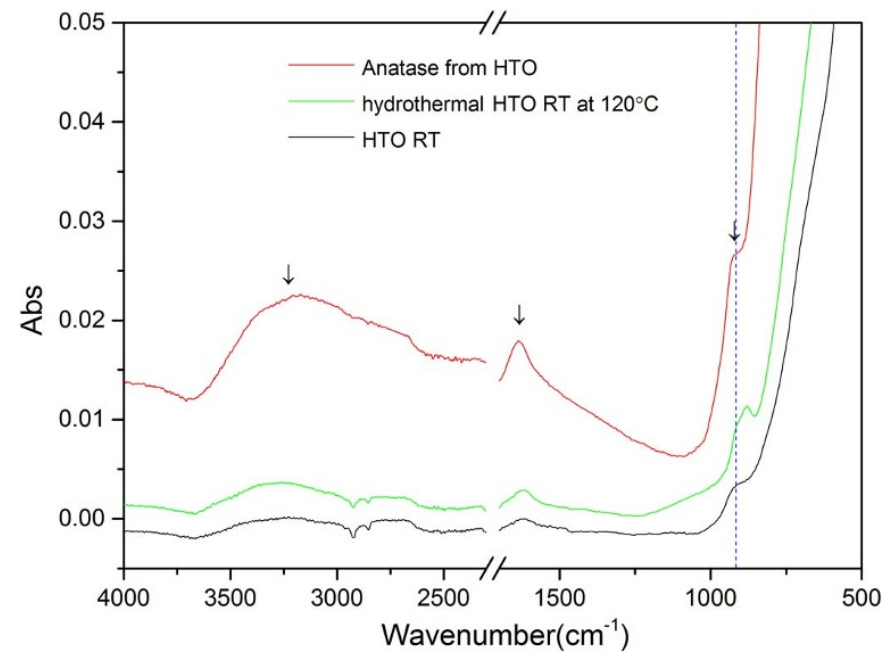

Figure 7 | FTIR spectrum of HTO RT before (black line) and after (green line) hydrothermal treatment at $120^{\circ} \mathrm{C}$ and anatase from HTO RT (red line). The vertical dotted line is placed at $920 \mathrm{~cm}^{-1}$.

lepidocrocite nanosheet ${ }^{25,26}$, which implies that the (001) surface of anatase has a similar chemistry as the (001) surface of lepidocrocitetype titanate. Arrouvel et al. found that the fully hydroxyl-covered surface state is less stable than the partially hydroxyl-covered surface state on the $\mathrm{TiO}_{2}$ (001) surface ${ }^{27}$. So our results indicate that protons were absorbed and participated in the formation of hydroxyl groups, i.e. the surface of the inner HTO layers became hydroxylated. The formation of hydroxyl groups provides an explanation why HTO HT swells under hydrothermal treatment. It is noteworthy that this intermediate state is interesting for the preparation of 2-dimensional HTO nanosheets, since the charges between the interlayers are neutralized, thus facilitating the loss of coherence between HTO planes. However, since the hydroxyl groups formed on the surface of the titanate layers are not stable, they can easily participate in the reaction of hydroxyl groups on adjacent titanate layers once the surface $\mathrm{OH}$ concentration is saturated, following the net reaction $2-\mathrm{OH} \rightarrow-\mathrm{O}-+\mathrm{H}_{2} \mathrm{O}$.

\section{Discussion}

The phase transformation from lepidocrocite-type titanate to anatase under hydrothermal treatment has been observed not only in layered titanates and exfoliated nanosheets, but also in titania nanotubes $^{1-4,28-32}$. The common conditions in those preparation procedures are that: 1) the crystal structure of the host titanate is lepidocrocite-type; 2) protons are present in the solution. Wen et al. observed that the phase transformation from lepidocrocite-type nanosheets to anatase occurred preferably under low basic, neutral, or acidic conditions ${ }^{11}$. Gao et al. observed that the electrical conductivity that was associated with the presence of interlayer $\mathrm{H}^{+}$ions decreased at the temperature at which the phase transformation from lepidocrocite-type nanotubes to anatase occurred ${ }^{31}$. These findings suggest that the concentration of surface hydroxyl groups which results from uptake of protons is a key factor for phase transformation of lepidocrocite-type titanate to anatase.

Based on our results the mechanism of phase transformation from HTO to anatase is thought to involve two steps. Firstly, protons are absorbed by the layered structure of HTO. They form hydroxyl groups of the (internal) surface of the titanate host layer of HTO. The data in figure 3 suggest that hydroxyl formation starts at low temperatures. Secondly, after the hydroxyl groups are formed, the topotactic reaction from layered HTO to anatase occurs. Adjacent hydroxyl groups located on two neighboring layers react with each other to form an oxo (-O-) bond between the layers, generating $\mathrm{H}_{2} \mathrm{O}$ as byproduct, and yielding anatase upon expulsion of water 


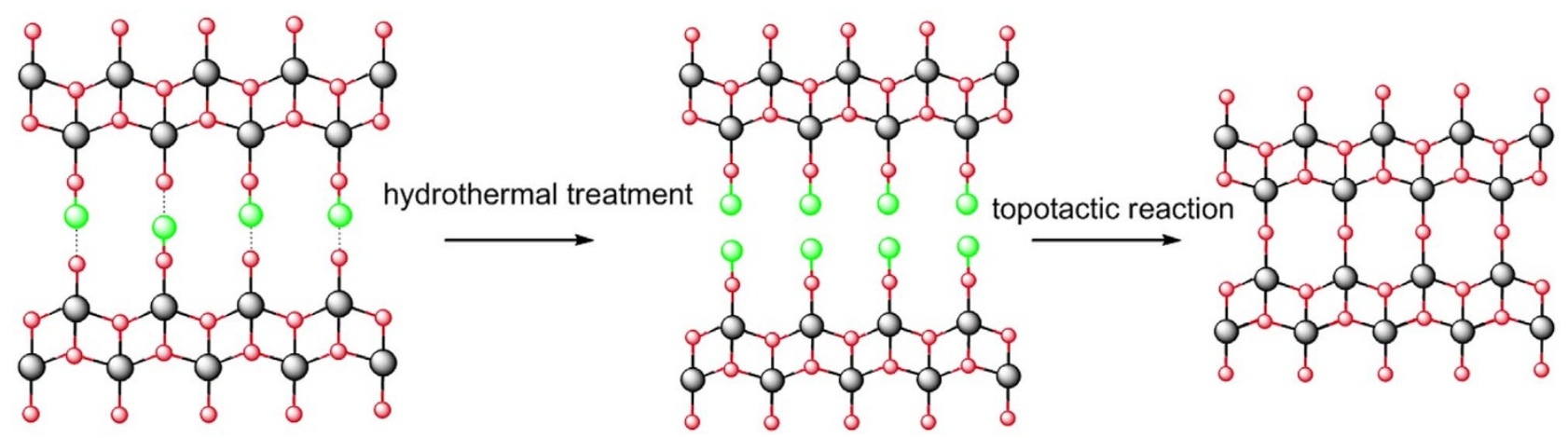

○ Oxygen atom

Titanium atom

$\mathrm{H}_{3} \mathrm{O}^{+}$or $\mathrm{H}^{+}$

Figure 8 | Schematic diagram of phase evolution of HTO from lepidocrocite-type layered titanate to anatase.

(Figure 2). The schematic diagram of phase transformation is shown in Figure 8.

In summary, we found that the inner surface of dry HTO is proton deficient. Our results suggest that the protons in HTO involve a hydrogen bond configuration in which the hydrogen atom forms a hydroxyl bond with one oxygen atom and a hydrogen bond with the other. The phase transformation from lepidocrocite-type titanate to anatase is a topotactic dehydration reaction between hydroxyl groups that are located on adjacent titanate layers. The phase evolution involves 1) proton uptake into the proton-deficient layered structure of HTO and formation of hydroxyl bonds on the inner layer of HTO, and 2) reaction between adjacent hydroxyl groups located on different layers, forming anatase-type $\mathrm{TiO}_{2}$ under expulsion of $\mathrm{H}_{2} \mathrm{O}$.

\section{Methods}

Materials. Titanium(IV) dioxide $\mathrm{TiO}_{2}$ (Ridel-de Haen), molybdenum(VI) oxide $\mathrm{MoO}_{3}$ (Sigma-Aldrich), anhydrous potassium carbonate $\mathrm{K}_{2} \mathrm{CO}_{3}$ (Fluka) and lithium carbonate $\mathrm{Li}_{2} \mathrm{CO}_{3}$ (Ridel-de Haen) had a purity of $99.0 \%$ or higher and were used as received. Demineralized water was used throughout the experiments.

Preparation of lepidocrocite-type protonated layered titanates. The $\mathrm{K}_{0.8}\left[\mathrm{Ti}_{1.73} \mathrm{Li}_{0.27} \mathrm{O}_{4}\right]$ precursor was obtained with a flux method as described by Tanaka et al. ${ }^{17}$ The resulting KLTO powder was washed 3 times in $250 \mathrm{~mL}$ water to remove $\mathrm{K}_{2} \mathrm{MoO}_{4}$. Then $5.5 \mathrm{~g} \mathrm{KLTO}$ powder was dispersed in a $2 \mathrm{~mol} / \mathrm{L} \mathrm{HNO}_{3}$ solution $(250 \mathrm{~mL})$ at room temperature while stirring. The acidic solution was replaced daily by a fresh one by decantation. After treatment for 3 days to completely remove all alkali metal ions ${ }^{15}$, the acid-exchanged crystals $\mathrm{H}_{1.07} \mathrm{Ti}_{1.73} \mathrm{O}_{4} \cdot \mathrm{nH}_{2} \mathrm{O}$ (HTO) were collected by filtration and washed with a copious quantity of pure water, then air dried, and finally slightly ground to get HTO powder (HTO RT). Part of the HTO RT powder was dried at $80^{\circ} \mathrm{C}$ to release all intercalated water in the interlayer space, so that finally a dried HTO powder was obtained (HTO HT).

Hydrothermal treatment of HTO. $0.1 \mathrm{~g}$ of HTO RT was weighted and mixed with $30 \mathrm{~mL}$ water without any additives and placed in a glass bottle for hydrothermal experiments. The closed glass bottles were placed in an oven at temperatures ranging from 60 to $140^{\circ} \mathrm{C}$ for $24 \mathrm{~h}$. Another part of the HTO RT powder with $30 \mathrm{~mL}$ water was hydrothermally treated at $120^{\circ} \mathrm{C}$ and then titrated with $\mathrm{HNO}_{3}$ solution $(2 \mathrm{~mol} / \mathrm{L})$ to a $\mathrm{pH}$ of 2.8. Then, this powder received hydrothermal treatment again.

Characterization. Powder X-ray diffraction (XRD) data were acquired on a Bruker D2 PHASER ( $\mathrm{Cu} \mathrm{K}$ r radiation with a wavelength of $0.15405 \mathrm{~nm}$ ). Measurements on wet state samples were conducted after vacuum filtration (glass microfiber filter, maximum pore size is limited to $1 \mu \mathrm{m}$ ) without further drying, and measurements on other samples were conducted after vacuum filtration with $24 \mathrm{~h}$ room temperature drying unless mentioned otherwise. Transmission electron microscopy (TEM) observation was performed on a Philips CM300ST-FEG at $300 \mathrm{kV}$, and the sample was supported on a carbon microgrid. The $\mathrm{pH}$ was measured by a Fisher Scientific Accumet Research AR15 pH meter. The Fourier transform infrared (FTIR) spectra were recorded by a Bruker Fourier Transform Infrared Spectrometer Model TENSOR 27 with a Pike GladiATR. The zeta potential data were measured by a Malvern Zetasizer Nano ZS. The sample was ultrasonicated for $10 \mathrm{~min}$ to get a nicely dispersed solution and the $\mathrm{pH}$ of the samples was titrated manually with $\mathrm{HCl}$ aqueous solution $(0.2 \mathrm{~mol} / \mathrm{L})$.

1. Carp, O., Huisman, C. L. \& Reller, A. Photoinduced reactivity of titanium dioxide. Prog. Solid State Chem. 32, 33-177 (2004).

2. Neo, C. Y. \& Ouyang, J. LiF-doped mesoporous $\mathrm{TiO}_{2}$ as the photoanode of highly efficient dye-sensitized solar cells. J. Power Sources 241, 647-653 (2013).

3. Abdelaal, M. Y. \& Mohamed, R. M. Novel Pd/TiO ${ }_{2}$ nanocomposite prepared by modified sol-gel method for photocatalytic degradation of methylene blue dye under visible light irradiation. J. Alloys Comp. 576, 201-207 (2013).

4. Mankidy, B. D., Joseph, B. \& Gupta, V. K. Photo-conversion of $\mathrm{CO}_{2}$ using titanium dioxide: enhancements by plasmonic and co-catalytic nanoparticles. Nanotechnology 24, 405402-405402 (2013).

5. Gao, X., Chen, J. \& Yuan, C. Enhancing the performance of free-standing $\mathrm{TiO}_{2}$ nanotube arrays based dye-sensitized solar cells via ultraprecise control of the nanotube wall thickness. J. Power Sources 240, 503-509 (2013).

6. Zhang, J. et al. $\mathrm{N}$-doped rutile $\mathrm{TiO}_{2}$ nano-rods show tunable photocatalytic selectivity. J. Alloys Comp. 575, 40-47 (2013).

7. Pan, J., Liu, G., Lu, G. Q. \& Cheng, H.-M. On the true photoreactivity order of $\{001\},\{010\}$, and $\{101\}$ facets of anatase $\mathrm{TiO}_{2}$ crystals. Angew. Chem. Int. Ed. 50, 2133-2137 (2011).

8. Diebold, U. The surface science of titanium dioxide. Surf. Sci. Rep. 48, 53-229 (2003).

9. Wen, P., Itoh, H., Tang, W. \& Feng, Q. Transformation of layered titanate nanosheets into nanostructured porous titanium dioxide in polycation solution. Micropor. Mesopor. Mater. 116, 147-156 (2008).

10. Pan, J. et al. Synthesis of anatase $\mathrm{TiO}_{2}$ rods with dominant reactive $\{010\}$ facets for the photoreduction of $\mathrm{CO}_{2}$ to $\mathrm{CH}_{4}$ and use in dye-sensitized solar cells. Chem. Commun. 47, 8361-8363 (2011).

11. Wen, P. H., Itoh, H., Tang, W. P. \& Feng, Q. Single nanocrystals of anatase-type $\mathrm{TiO}_{2}$ prepared from layered titanate nanosheets: Formation mechanism and characterization of surface properties. Langmuir 23, 11782-11790 (2007).

12. Feng, Q., Hirasawa, M. \& Yanagisawa, K. Synthesis of crystal-axis-oriented $\mathrm{BaTiO}_{3}$ and anatase platelike particles by a hydrothermal soft chemical process. Chem. Mater. 13, 290-296 (2001).

13. Wen, P., Ishikawa, Y., Itoh, H. \& Feng, Q. Topotactic transformation reaction from layered titanate nanosheets into anatase nanocrystals. J. Phys. Chem. C 113, 20275-20280 (2009).

14. Yin, S., Uchida, S., Fujishiro, Y., Aki, M. \& Sato, T. Phase transformation of protonic layered tetratitanate under solvothermal conditions. J. Mater. Chem. 9, 1191-1195 (1999).

15. Sasaki, T. et al. A Mixed Alkali Metal Titanate with the lepidocrocite-like layered structure. Preparation, crystal structure, protonic form, and Acid-Base intercalation properties. Chem. Mater. 10, 4123-4128 (1998).

16. Sasaki, T. et al. Preparation and Acid-Base properties of a protonated titanate with the lepidocrocite-like layer structure. Chem. Mater. 7, 1001-1007 (1995).

17. Tanaka, T., Ebina, Y., Takada, K., Kurashima, K. \& Sasaki, T. Oversized titania nanosheet crystallites derived from flux-grown layered titanate single crystals. Chem. Mater. 15, 3564-3568 (2003). 
18. Sasaki, T., Watanabe, M., Hashizume, H., Yamada, H. \& Nakazawa, H. Macromolecule-like aspects for a colloidal suspension of an exfoliated titanate. Pairwise association of nanosheets and dynamic reassembling process initiated from it. J. Am. Chem. Soc. 118, 8329-8335 (1996).

19. Jiang, J., Oberdörster, G. \& Biswas, P. Characterization of size, surface charge, and agglomeration state of nanoparticle dispersions for toxicological studies. J. Nanopart. Res. 11, 77-89 (2009).

20. Casarin, M., Vittadini, A. \& Selloni, A. First principles study of hydrated/ hydroxylated $\mathrm{TiO}_{2}$ nanolayers: From isolated sheets to stacks and tubes. ACS Nano 3, 317-324 (2009).

21. Sasaki, T., Komatsu, Y. \& Fujiki, Y. Protonated pentatitanate: preparation, characterizations and cation intercalation. Chem. Mater. 4, 894-899 (1992).

22. Adachi-Pagano, M., Forano, C. \& Besse, J.-P. Delamination of layered double hydroxides by use of surfactants. Chem. Commun., 91-92 (2000).

23. Sasaki, T., Izumi, F. \& Watanabe, M. Intercalation of pyridine in layered titanates. Chem. Mater. 8, 777-782 (1996).

24. Sasaki, T., Komatsu, Y. \& Fujiki, Y. A new layered hydrous titanium dioxide $\mathrm{H}_{\mathrm{x}} \mathrm{Ti}_{2-\mathrm{x} / 4} \mathrm{O}_{4} \cdot \mathrm{H}_{2} \mathrm{O}$. Chem. Commun., 817-818 (1991).

25. Orzali, T., Casarin, M., Granozzi, G., Sambi, M. \& Vittadini, A. Bottom-up assembly of single-domain Titania nanosheets on $(1 \times 2)-\mathrm{Pt}(110)$. Phys. Rev. Lett. 97, 156101 (2006).

26. Vittadini, A. \& Casarin, M. Ab initio modeling of $\mathrm{TiO}_{2}$ nanosheets. Theor. Chem. Acc. 120, 551-556 (2008)

27. Arrouvel, C., Digne, M., Breysse, M., Toulhoat, H. \& Raybaud, P. Effects of morphology on surface hydroxyl concentration: a DFT comparison of anatase$\mathrm{TiO}_{2}$ and $\gamma$-alumina catalytic supports. J. Catal. 222, 152-166 (2004).

28. Nian, J. N. \& Teng, H. S. Hydrothermal synthesis of single-crystalline anatase $\mathrm{TiO}_{2}$ nanorods with nanotubes as the precursor. J. Phys. Chem. B 110, 4193-4198 (2006).

29. Mao, Y. B. \& Wong, S. S. Size- and shape-dependent transformation of nanosized titanate into analogous anatase titania nanostructures. J. Am. Chem. Soc. 128, 8217-8226 (2006).

30. Feng, Q., Hirasawa, M., Kajiyoshi, K. \& Yanagisawa, K. Hydrothermal soft chemical synthesis and particle morphology control of $\mathrm{BaTiO}_{3}$ in surfactant solutions. J. Am. Ceram. Soc. 88, 1415-1420 (2005).
31. Gao, T., Fjeld, H., Fjellvag, H., Norby, T. \& Norby, P. In situ studies of structural stability and proton conductivity of titanate nanotubes. Energy Environ. Sci. 2, 517-523 (2009)

32. Zhao, B., Chen, F., Jiao, Y. \& Zhang, J. Phase transition and morphological evolution of titania/titanate nanomaterials under alkalescent hydrothermal treatment. J. Mater. Chem. 20, 7990-7997 (2010).

\section{Acknowledgments}

The authors acknowledge the financial support of the Chemical Sciences division of The Netherlands Organization for Scientific Research (NWO-CW) and the program of China Scholarships Council (CSC, No.2011704003). The authors thank Mr. Rico Keim for performing the TEM experiments. The authors also want to thank Ms. Liu Yang for her help in the preparation of figures.

\section{Author contributions}

H.Y. conducted the experiments and analyzed the results. H.Y. and J.E.T.E. wrote the main manuscript text and H.Y. prepared figures 1-8. R.B. contributed to the FTIR data acquisition and useful discussion. Z.L. contributed to the analysis of TEM data and useful discussion. All authors reviewed the manuscript.

\section{Additional information}

Competing financial interests: The authors declare no competing financial interests.

How to cite this article: Yuan, H.Y., Besselink, R., Liao, Z.L. \& ten Elshof, J.E. The swelling transition of lepidocrocite-type protonated layered titanates into anatase under hydrothermal treatment. Sci. Rep. 4, 4584; DOI:10.1038/srep04584 (2014).

This work is licensed under a Creative Commons Attribution-NonCommercialShareAlike 3.0 Unported License. The images in this article are included in the article's Creative Commons license, unless indicated otherwise in the image credit; if the image is not included under the Creative Commons license, users will need to obtain permission from the license holder in order to reproduce the image. To view a copy of this license, visit http://creativecommons.org/licenses/by-nc-sa/3.0/ 